\title{
O uso do Software HagáQuê nos anos iniciais do ensino fundamental: práticas de letramento em contextos digitais
}

OLIVEIRA, Aletheia Machado de ${ }^{1}$

\section{RESUMO}

O presente trabalho tem como objetivo analisar se o uso do software educativo HagáQuê auxilia os alunos no processo de leitura e escrita em contexto digital. Com uma metodologia de caráter qualitativa e pesquisa de campo com observação participante direta intensiva, o estudo envolveu professora e alunos em atuação no 5 ano do Ensino Fundamental pertencentes à rede municipal de ensino localizada no município de Minas Gerais. Os dados revelam que o trabalho articulado com a ferramenta tecnológica computador deve pautar-se através de um processo integrado, crítico, reflexivo e elaborado à luz dos objetivos educacionais. Verificou-se que a análise das histórias em quadrinhos criadas pelos alunos com a ajuda do software HagáQuê revela efetividade da prática da leitura e escrita de forma contextual. Conclui-se que o software educativo HagáQuê mostrou-se ser uma ferramenta interessante para esse processo ao provocar um interesse para uma maior aproximação com as funções sociais da linguagem.

Letramento. Software educativo. HagáQuê.

The use of HagáQuê software in the early years of elementary school: literacy practices in digital contexts

\section{ABSTRACT}

This paper aims to analyze whether the use of educational software HagáQuê helps students in the process of reading and writing in a digital context. With a qualitative methodology and field research with intensive direct participant observation, the study involved a teacher and students working in the 5th year of elementary school belonging to the municipal school system located in the municipality of Minas Gerais. The data reveal that the work articulated with the computer technological tool must be guided by an integrated, critical, reflective and elaborated process in the light of educational objectives. It was found that the analysis of the comic books created by the students with the help of the HagáQuê software reveals the effectiveness of the practice of reading and writing in a contextual way. It is concluded that the educational software HagáQuê

\footnotetext{
${ }^{1}$ Doutoranda do programa de pós-graduação em educação, Faculdade de Ciências e Tecnologia, UNESP/Campus Presidente Prudente. Professora de informática na rede municipal de Juiz de Fora. E-mail: aletheiaoliveirajf@gmail.com. Lattes:

http://lattes.cnpq.br/0209852490245633. Orcid: https://orcid.org/0000-0002-1058-0817.

\begin{tabular}{l|l} 
REVISTA & $\begin{array}{l}\text { Interritórios | Revista de Educação } \\
\text { interritórios }\end{array}$ \\
Cniversidade Federal de Pernambuco, \\
Caruaru, BRASIL | V.6 N.12 [2020]
\end{tabular}
}


proved to be an interesting tool for this process by provoking an interest in a closer relationship with the social functions of language.

Literacy. Educacional Software. HagáQuê.

El uso del software HagáQuê en los primeros años de la escuela primaria: prácticas de alfabetización en contextos digitales

\section{RESUMEN}

Este artículo tiene como objetivo analizar si el uso del software educativo HagáQuê ayuda a los estudiantes en el proceso de lectura y escritura en contexto digital. Con una metodología cualitativa e investigación de campo con observación participante directa intensiva, el estudio involucró a una profesora y alumnos que estudian en el 5to año de la escuela primaria perteneciente al sistema escolar municipal ubicado en el municipio de Minas Gerais. Los datos revelan que el trabajo articulado con la herramienta tecnológica computadora debe ser guiado por un proceso integrado, crítico, reflexivo y elaborado a la luz de los objetivos educativos. Se averiguó que el análisis de las historietas creadas por los estudiantes con la ayuda del software HagáQuê revela efectividad de la práctica de la lectura y la escritura de manera contextual. Se concluye que el software educativo HagáQuê resultó ser una herramienta interesante para este proceso al despertar el interés por una relación más cercana con las funciones sociales del lenguaje.

Alfabetización. Software educativo. HagáQuê.

\section{L'utilizzo del software HagáQuê nei primi anni della scuola primaria: pratiche di alfabetizzazione in contesti digitali}

\section{SOMMARIO}

Questo articolo mira ad analizzare se l'uso del software educativo HagáQuê aiuta gli studenti nel processo di lettura e scrittura in un contesto digitale. Utilizzando una metodologia qualitativa e una ricerca sul campo con un'intensa osservazione diretta dei partecipanti, lo studio ha coinvolto un insegnante e studenti che studiano nel $5^{\circ}$ anno della scuola primaria appartenente al sistema scolastico municipale situato nel comune di Minas Gerais. Dai dati emerge che il lavoro articolato con lo strumento informatico deve essere guidato da un processo integrato, critico, riflessivo ed elaborato alla luce degli obiettivi formativi. Si è riscontrato che l'analisi dei fumetti creati dagli studenti con l'aiuto del software HagáQuê rivela l'efficacia della pratica di lettura e scrittura in modo contestuale. $\mathrm{Si}$ è concluso che il software educativo HagáQuê si è rivelato uno strumento interessante per questo processo risvegliando l'interesse in una relazione più stretta con le funzioni sociali del linguaggio.

Alfabetizzazione. Software educativo. Fare. 


\section{INTRODUÇÃO}

As atividades relacionadas ao ensino e aprendizagem da disciplina de Língua Portuguesa nas escolas apontam para o domínio da língua oral e escrita. Tal fato possibilita ao aluno expressar, defender, partilhar e refletir diferentes visões de mundo para a produção do conhecimento. Por isso, ao trabalhar com os conteúdos dessa disciplina, é fundamental criar condições para 0 desenvolvimento da capacidade de uso eficaz da Língua Portuguesa através do contato com diferentes tipos de materiais e estratégias de ensino, para que os alunos despertem para a leitura e escrita de forma significativa e eficiente.

De acordo com os Parâmetros Curriculares Nacionais de Língua Portuguesa (1997), para que os alunos adquiram competências em relação à linguagem, faz-se necessário conhecer diferentes variedades linguísticas; desenvolver a capacidade de compreender os textos orais e escritos; valorizar a leitura como fonte de informação e melhorar as relações pessoais; utilizar a linguagem como instrumento de aprendizagem e ter capacidade de análise crítica. O domínio desses aspectos caracteriza, segundo o documento, um movimento metodológico de ação/reflexão/ação quando se pretende que o aluno adquira tais habilidades e competências para serem aplicadas em situações da vida cotidiana.

Desenvolver a capacidade de ler, analisar, interpretar, criticar, observar, refletir e criar são pontos essenciais para que os alunos alcancem as competências e habilidades linguísticas para a vida diária e sua inserção social como cidadão competente no uso da Língua Portuguesa em quaisquer contextos, seja, portanto, letrado. Torna-se inevitável, então, questionar por que não aliar o uso da tecnologia digital ao conteúdo de Língua Portuguesa?

No campo educacional, a incorporação das tecnologias digitais vem se solidificando e se destacando trazendo grandes possibilidades para a prática pedagógica. Gadotti (2000) nos diz que tais tecnologias possibilitaram a criação de novos espaços de conhecimento, democratização da informação, maior conectividade, ensinar pensar, saber pesquisar, saber articular conhecimento e prática, ser aprendiz autônomo.

Complementando as palavras do autor, percebe-se que ao apropriar-se das tecnologias digitais estas auxiliam no processo de ensino e aprendizagem, promove a inclusão em contextos digitais, trabalha novas abordagens metodológicas, torna o ensino mais motivador e dinâmico e promove atitude investigativa, cooperativa e reflexiva, pontos positivos para o desenvolvimento da linguagem oral e escrita dos alunos.

Dentre as inúmeras tecnologias digitais existentes, temos o computador como elemento marcante e atrativo para os alunos e presente nas escolas. Esta ferramenta apresenta características importantes como interatividade, 
transmissão, distribuição e compartilhamento de informação, além de enriquecer o processo de aprendizagem. Tal fato pode ser corroborado quando Marinho (2013) nos diz que dar um sentido à tecnologia no contexto escolar, em especial o computador, significa compreendê-la como ferramenta física, simbólica, social, a serviço do saber e de um saber-fazer que propiciará a construção de conhecimentos e de novas aprendizagens.

Interligado a essa ferramenta, temos os softwares educativos como mais um recurso pedagógico utilizado pelo professor que atua no laboratório de informática e em parceria com os conteúdos trabalhados pelo professor regente de sala de aula, como instrumento didático facilitador da aprendizagem.

Nesse contexto, contamos com inúmeros softwares educativos que podem auxiliá-los nesse processo. Valente (1999) pontua que existem diversos tipos de softwares que vão desde os de uso aberto, de autoria ou aplicativos. Em todos esses casos, o importante é a resolução de problemas ou a realização de tarefas. O que está sendo trabalhado via computador permite ao aluno buscar novos conteúdos e estratégias para ampliar o nível de conhecimento que já possui sobre o assunto.

Lisboa (2013) corrobora com o autor supracitado e acrescenta que a exploração de softwares educativos pode contribuir com a aquisição de habilidades cognitivas, além de motivar, estimular a criatividade e imaginação, desenvolver atenção/concentração, tomada de decisões, correspondência de idéias, abstração, entre outros. Esses softwares devem dialogar com os conteúdos didáticos e serem analisados previamente com o professor de informática para que os objetivos propostos sejam alcançados com sucesso.

Diante de tais apontamentos, o presente trabalho justifica-se porque ao perceber que muitos alunos encontram dificuldades em expressar-se com objetividade e clareza e na própria escrita das palavras, deseja sugerir novas formas pedagógicas para um ensino/aprendizagem mais interessante para os alunos ao usarmos softwares educativos em parceria com os conteúdos da disciplina de Língua Portuguesa.

A aplicabilidade de softwares educativos ao campo educacional tendo em vista um ensino mais atraente, permite ao professor fazer conexões entre os conhecimentos adquiridos em sala de aula e o recurso tecnológico trabalhado no laboratório de informática. Um trabalho que promova o uso consciente da leitura e escrita, com significado, como afirmam Cardoso e Ednir (1998, p. 51), que para saber escrever e ler o aluno necessita não é só fazer ditados com palavras e frases corretas, mas que saibam empregar as palavras nas ocasiões certas, que dominem as regras de cada tipo de texto e que encontrem prazer na relação com o texto, "[...] elemento libertador do pensamento". 
A partir das reflexões apresentadas, estabeleceu-se como objetivo geral analisar se o uso do software educativo HagáQuê auxilia os alunos no processo de leitura e escrita em contexto digital.

Do propósito principal, objetiva-se especificamente que este trabalho analisa os conceitos de alfabetização e letramento em contextos digitais, conceitue software educativo, descreva o software educativo HagáQuê, bem com apresente os resultados a serem aplicados em uma escola da rede municipal de Juiz de Fora incluindo o planejamento, a caracterização da escola e dos alunos e as ações desenvolvidas.

\section{Alfabetização e letramento em contextos digitais}

A Língua Portuguesa é expressa em diferentes linguagens e em ambientes diversos na sociedade. Essas linguagens são utilizadas para falar, ouvir, escrever e ler, manifestar o pensamento, as ideias. Conhecê-las não é uma exigência apenas da escola, mas uma necessidade social de cada pessoa. Dentre suas manifestações, a escrita é a que mais oferece dificuldades aos alunos dos anos iniciais. Na vida diária, a leitura é mais comum, e, principalmente a linguagem não-verbal por ser mais atraente.

Nesse contexto, devemos entender os conceitos de alfabetização e letramento que emergem sobre os domínios de habilidades relacionados à leitura e escrita e que são tão importantes para os alunos relacionarem com as questões cotidianas da sua vida diária.

Neste sentido considero oportuna a discussão apresentada no texto intitulado O que é letramento? e publicado na matéria do jornal Diário da Escola, página 03, de Santo André, ao informar ao leitor sobre a importância do sentido que devemos dar ao ensino da Língua Portuguesa. Em um trecho do texto, este nos diz que "[...] não basta apenas basta aprender a ler e escrever, é necessário mais que isso para ir além da alfabetização funcional (denominação dada às pessoas que foram alfabetizadas, mas não sabem fazer uso da leitura e da escrita)." Ou seja, é preciso ensinar a ler e escrever dentro de um contexto que faça sentido para o aluno e com todas as disciplinas envolvidas nesse processo, não sendo apenas de responsabilidade do docente de Língua Portuguesa.

Os Parâmetros Curriculares Nacionais - Língua Portuguesa nos lembra tal reflexão ao explicitar que devemos viabilizar aos alunos o acesso a textos de diferentes disciplinas para que estes sujeitos sejam capazes de argumentar, criticar, compreender, comparar, condição para o bom aprendizado da leitura e escrita. Ao declarar que o ensino da Língua Portuguesa tem como propósito a "[...] expansão das possibilidades do uso da linguagem [...]", atribui-se que 
devemos desenvolver nos alunos quatro habilidades linguísticas básicas, a saber: falar, escutar, ler e escrever. (BRASIL, 1997, p. 30).

Torna-se necessário, então, entender os conceitos alfabetização e letramento para depois interligarmos ao contexto digital e que será apresentado no trabalho com base nos estudos de Magda Soares.

Soares $(1998,2003 b)$ pondera que os termos alfabetização e letramento, embora distintos, são interdependentes e indissociáveis. Afirma que é um equívoco dissociá-los no quadro das atuais concepções psicológicas, linguísticas e psicolinguísticas de leitura e escrita, sendo necessário rever os processos de ensino que tem predominado nas salas de aula de muitas escolas. Enquanto o primeiro termo refere-se à aquisição do sistema convencional de escrita, o segundo refere-se ao desenvolvimento de competências e habilidades sobre o uso consciente da leitura e escrita em práticas sociais, ou seja, saber opinar, relacionar ideias, defender, argumentar sobre as questões que se fazem presente em nossa sociedade como, por exemplo, as discussões sobre política, educação, etnia, relações interpessoais, entre outras.

Nas palavras da autora supracitada, o que se propõe é:

[...] em primeiro lugar, a necessidade de reconhecimento da especificidade da alfabetização, entendida como processo de aquisição e apropriação do sistema da escrita, alfabético e ortográfico; em segundo lugar, e como decorrência, a importância de que a alfabetização se desenvolva num contexto de letramento - entendido este, no que se refere à etapa inicial da aprendizagem da escrita, como a participação em eventos variados de leitura e de escrita, e o consequente desenvolvimento de habilidades de uso da leitura e da escrita nas práticas sociais que envolvem a língua escrita, e de atitudes positivas em relação a essas práticas; em terceiro lugar, o reconhecimento de que tanto a alfabetização quanto 0 letramento têm diferentes dimensões, ou facetas, a natureza de cada uma delas demanda uma metodologia diferente, de modo que a aprendizagem inicial da língua escrita exige múltiplas metodologias, algumas caracterizadas por ensino direto, explícito e sistemático - particularmente a alfabetização, em suas diferentes facetas - outras caracterizadas por ensino incidental, indireto e subordinado a possibilidades e motivações das crianças; em quarto lugar, a necessidade de rever e reformular a formação dos professores das séries iniciais do ensino fundamental, de modo a torná-los capazes de enfrentar o grave e reiterado fracasso escolar na aprendizagem inicial da língua escrita nas escolas brasileiras. (SOARES, 2003b, p. 1617).

Nesta citação é possível discernir a forma como os termos alfabetização e letramento devem ser compreendidos pelos professores e como podem ser trabalhados junto aos seus alunos e, porque não, serem trabalhados no contexto 
digital, nesse novo ambiente em que a efetividade da prática leitura/escrita passa a ocorrer de forma mais atraente e contextual no universo digital. Através da associação tecnologia/ensino da Língua Portuguesa, os professores têm mais uma possibilidade de explorar os conteúdos trabalhados com esse recurso, proporcionando novas formas de transmissão e articulação do conhecimento adquirido em sala de aula.

Faço ainda mais uma menção ao texto de Alves, Silva e Santos (2013, p. 04), ao afirmarem que o processo de alfabetização e letramento não precisa ocorrer apenas no contexto da sala de aula, mas também no contexto digital. Sendo um processo contínuo, alfabetização e letramento tem sido favorecida pelo uso das novas tecnologias da informação e comunicação ao oportunizar aos alunos experimentações, desafios e novas possibilidades de usos sociais da leitura e escrita. As autoras ainda chamam a atenção para a forma diferenciada como esse processo se configura, a saber: no contexto da sala de aula há a preocupação "[...] em reproduzir o ensino do código, proporcionando um auxílio na interpretação destes sinais [...]" e no contexto digital o enfoque está em potencializar a capacidade de aprendizagem da leitura e escrita desses alunos, "[...] desencadeando processos de ensino/aprendizagem cada vez mais interativos, dinâmicos e plurais, articulados ao contexto de uso da linguagem pelos sujeitos envolvidos."

Para tanto, contamos com uma variedade de softwares educativos destinados ao ensino da disciplina de Língua Portuguesa e que podem ser explorados pelo professor visando contribuir para o processo de alfabetização e letramento desses alunos, além de apresentar um contexto envolvente, ter ligação com os interesses dos alunos, ser estimulante, incentivar a interação social, o trabalho em equipe e misturar conteúdo e diversão.

\section{O que é Software Educativo?}

Diante da grande variedade de softwares educativos existentes no mercado, é fato sua utilização no processo educacional. Mas o que é software educativo?

Nas palavras de Oliveira, Costa e Moreira (2001, p. 46), software educativo ou Programa Educativo por Computador não é o mesmo que software educacional. Enquanto que o software educacional é um produto educacional, empregado tanto em procedimentos administrativos ou escolares, o software educativo é considerado uma categoria deste, cujo objetivo é favorecer o processo ensino e aprendizagem, permitindo ao aluno a construção de determinado conteúdo didático como destacam os autores ao pontuarem que a essência do software educativo "[...] é o seu caráter didático que busca favorecer o conhecimento pelo aluno". 
Esses mesmos autores apresentam algumas características que poderão ajudar o professor a selecionar o software educativo mais adequado à sua proposta educacional, a saber: presença de uma fundamentação pedagógica; finalidade didática correlacionada ao currículo; interação aluno/programa; facilidade de uso e atualização quanto ao estado da arte. Como instrumento didático, Soffa e Alcântara (2008) afirmam que o uso desse recurso deve ser empregado na construção e assimilação do conhecimento dos aprendizes, de forma responsável, com potencialidades pedagógicas e integralizadas com o trabalho realizado em sala de aula, não sendo aplicado somente para passar o tempo.

Prado (2011) certifica que sua empregabilidade precisa ser encarada como um meio de aprendizagem e não apenas como entretenimento. Por meio dos softwares educativos, os alunos podem trabalhar em grupo; é possível avaliar o desempenho de cada aluno durante as jogadas; contribui para 0 levantamento de hipóteses e modificação dos esquemas de conhecimento, além do caráter lúdico.

Torna-se necessário ainda mencionar a relação de uso dos softwares educativos com as concepções de aprendizagem. No que diz respeito à concepção behaviorista, sua característica foi adaptada aos softwares através de repetição, aprovações e reprovações, passividade, visando aumentar 0 desempenho do aprendiz em sua aprendizagem. Com o ensino tecnicista, treinamento e memorização, como saber ligar ou desligar um computador, abrir programas, foram alguns aspectos norteadores do uso do computador na educação. Baseada em proporcionar ao aprendiz a construção do conhecimento e ser sujeito de sua própria aprendizagem de forma dinâmica, as teorias interacionistas ganharam evidência. (SILVA et al., 2014; OLIVEIRA, COSTA e MOREIRA, 2001).

Diante desse panorama, o uso de softwares educativos dentro da perspectiva interacionista é considerado um excelente caminho por convidar o aluno a ser protagonista de sua própria aprendizagem. Esse aluno tem a oportunidade de aprender o conceito ou o conteúdo embutido no programa de forma divertida e educativa.

Em se tratando da disciplina de Língua Portuguesa, contamos com uma variedade de softwares educativos que auxiliam os professores nesse processo. Dentre eles, temos o software HagáQuê e que se constitui na modalidade de software de autoria. Porém, antes de discutirmos sobre esse assunto faz-se necessário refletir sobre o uso e a importância das histórias em quadrinhos no ambiente escolar.

\section{História em quadrinho no ambiente escolar}


As histórias em quadrinhos estão presentes no cotidiano das crianças, dos jovens e adultos e utilizados para diversos fins, seja em anúncios, campanhas, ilustração nos livros didáticos, jornais, revistas e, atualmente, na Internet. No ambiente escolar, podemos verificar sua presença nos livros didáticos e na biblioteca.

Guimarães (2001) conceitua história em quadrinhos como

[...] forma de expressão artística que tenta representar um movimento através do registro de imagens estáticas. Assim, é História em Quadrinhos toda produção humana, ao longo de toda sua História, que tenha tentado narrar um evento através do registro de imagens, não importando se esta tentativa foi feita numa parede de caverna há milhares de anos, numa tapeçaria, ou mesmo numa única tela pintada. Não se restringe, nesta caracterização, o tipo de superfície empregado, o material usado para o registro, nem o grau de tecnologia disponível. (GUIMARÃES, 2001, p. 03).

Compõem o quadro dos chamados narrativos, podendo entreter ou veicular algum tipo de mensagem instrucional. Enredo, personagens, tempo, lugar e desfecho são os elementos básicos desse tipo de gênero textual. Os balões de formas e tipos variados servem de suporte para os diálogos e devem ser entendidos como representação da fala ou pensamento. Transmitem mensagens de forma atraente e eficiente e, por isso, contribuem para que as atividades de leitura e escrita possam ser estimulantes. (SILVA, 2012).

Os Parâmetros Curriculares Nacionais - Língua Portuguesa apresentam em seu texto esse recurso como gênero discursivo adequado para trabalhar tanto com a linguagem oral quanto a escrita no primeiro e segundo ciclo do Ensino Fundamental, objetivando que os alunos sejam capazes de, dentre os vários elencados no documento, "[...] utilizar a linguagem para expressar sentimentos, experiências e ideias; produzir textos escritos, coesos e coerentes, dentro dos gêneros previstos para o ciclo, ajustados a objetivos e leitores determinados. (BRASIL, 1997, p. 75).

No que tange ao uso no ambiente escolar, Gonçalves e Lammel (2013) nos diz que existem várias possibilidades de emprego das histórias em quadrinhos na educação. Sua utilização possibilita que os alunos apreciem, reflitam e criem histórias, tornando o processo educativo mais significativo. Através de uma experiência com alunos de faixa etária entre 08 e 09 anos, os autores puderam concluir que houve um grande interesse por parte dos alunos na criação e edição das histórias em quadrinhos, maior interatividade e criatividade.

\section{O Software Educativo Hagáquê}


Oriundo de um projeto de pesquisa de mestrado por Silvia Amélia Bim (1999-2001), foi concebido pelo Instituto de Computação da Unicamp. Seu objetivo principal é auxiliar no processo de alfabetização através da produção textual, contribuindo para incentivar a leitura e, por consequência, estimular a língua escrita. O público alvo constitui-se por crianças que estejam em fase de alfabetização ou não.

Discorrendo sobre o HagáQuê, constitui-se na modalidade de software de autoria $^{2}$ e de uso gratuito. Apresenta uma linguagem simples, com interface agradável e colorida, idioma em português brasileiro, de fácil instalação, encontra-se disponível para download ${ }^{3}$ na Internet. É compatível com o sistema operacional Windows e Linux Educacional.

As histórias criadas nesse software podem ser retomadas a qualquer instante e editadas no próprio HagáQuê. Essas histórias editadas aceitam a importação de algumas figuras e a anexação de sons, além da opção de publicar na Internete de impressão. Podem ser salvas em múltiplos arquivos de imagem, texto e som, além de um arquivo de controle (só aberto pelo software). (FERREIRA; FRADE, 2010).

Em relação aos aspectos pedagógicos, o software HagáQuê possibilita a autoria, interatividade, contribuição para a autoestima, criatividade e autonomia dos alunos. Além disso, permite aos alunos compor diferentes personagens, cenários, usar diferentes tipos de balões da fala e do pensamento, onomatopéias, conforme o interesse do aluno. Outro ponto a ser destacado é a concepção epistemológica interacionista que se configura no software em análise, pois

- a criança tem papel ativo e decide que direção tomar;

- a criança tem acesso à informações legíveis;

- o controle da mídia pela criança dá-se de forma clara e explícita;

- as atividades podem propiciar o desenvolvimento do senso crítico e estimular o pensamento;

- a mídia instiga a criança ao imaginário/subjetivação;

- a mídia favorece a elaboração do raciocínio lógico e memorização;

- a mídia estimula a criatividade, o espírito investigativo e observador de forma lúdica e recreativa. (FERREIRA; FRADE, 2010, p. 24).

\footnotetext{
${ }^{2}$ Software de autoria é aquele que propicia ao aluno a seleção, produção e construção do material com significado.

${ }^{3}<$ http://www.nied.unicamp.br/?q=content/hag\%C3\%A1qu\%C3\%AA> 
Com um grande potencial, o software educativo HagáQuê apresenta possibilidades efetivas para tornar o processo de leitura e escrita mais agradável e interessante para os alunos, visto que hoje eles têm grande interesse por atividades que são mediadas no contexto digital.

\section{Metodologia}

O trabalho pautou-se na abordagem qualitativa, do tipo descritiva, por ser considerada a mais apropriada à perspectiva deste estudo. Bogdan e Biklen (1994) enumeram algumas características essenciais desse estilo de pesquisa, a saber: tem no ambiente natural a fonte direta dos dados; a valorização do contexto; é descritiva; o centro de preocupação é o processo e não os resultados; enfatiza que métodos e teorias devem estar em consonância com aquilo que se estuda; entre outros.

Do ponto de vista dos procedimentos metodológicos, optou-se pela pesquisa bibliográfica e pesquisa de campo com observação participante direta intensiva. O primeiro procedimento reuniu informações em relação ao tema a partir de fontes secundárias, ou seja, foi consultado fontes nacionais relatadas em textos teóricos, artigos científicos e anais de encontro científicos para subsidiar o assunto apresentado. A escolha pelo segundo procedimento ocorreu em função da possibilidade de extrair dados e informações diretamente da realidade estudada, garantindo assim a credibilidade do material a ser analisado.

Para tanto, o trabalho foi aplicado tendo como público-alvo alunos do $5^{\circ}$ ano do Ensino Fundamental e campo de pesquisa uma escola da rede municipal de Juiz de Fora. Fotografias do ambiente em que a pesquisa foi aplicada, as histórias produzidas, a caracterização da escola e dos alunos em que o software HagáQuê foi aplicado e as ações desenvolvidas serão os materiais didáticos a serem apresentados e analisados à luz do referencial teórico a ser discutido. Reiteramos que os pressupostos éticos foram levados em consideração após os pais dos alunos terem assinado um termo de autorização de publicação das imagens e aprovação pelo Comitê de Ética. A escola em que foi desenvolvida a atividade possui um documento próprio para autorização de uso de imagens, com devolutiva positiva pelos estudantes.

\section{Resultados e discussões}

Este trabalho contou com a participação de uma professora do Ensino Fundamental que atuava em sala de aula, com a disciplina de Língua Portuguesa. O planejamento foi dividido em duas etapas. A primeira etapa consistiu na apresentação do trabalho à coordenação e à professora da escola. 
Nessa etapa, foi apresentado a essa professora o software educativo HagáQuê e sua funcionalidade. Ela, também, teve a oportunidade de aprender como usar a ferramenta e assim poder articular com alguma atividade realizada em sala de aula. Os encontros aconteceram quando essa professora estava em momentos livres na escola.

$\mathrm{Na}$ segunda etapa, em conversa com a pesquisadora, a professora escolheu trabalhar com o tema Meio Ambiente na criação de histórias em quadrinhos, articulada com a atividade sobre consciência ambiental que estava sendo trabalhada em forma de textos em sala de aula com os alunos. Ficou acordado que a turma iria ao laboratório de informática duas vezes por semana, com duração de 60 minutos cada aula, totalizando quatro encontros.

No que tange à caracterização da escola, esta localiza-se na zona leste de Minas Gerais. Apresenta uma boa infraestrutura, contemplando de forma satisfatória a todos os alunos da comunidade em que está inserida. Funciona em dois turnos, manhã e tarde, atendendo alunos da Educação Infantil de $1^{\circ}$ e $2^{\circ}$ período e Ensino Fundamental de $1^{\circ}$ ao $9^{\circ}$ ano.

Em seu Projeto Político Pedagógico, constata-se que há um projeto destinado ao uso do laboratório de informática pelos alunos e docentes da escola. Os objetivos do mesmo são promover a inclusão digital, propiciar um aprendizado mais interativo e motivador e proporcionar aos professores alternativas para a realização de um trabalho mais produtivo e dinâmico com os alunos.

No que se refere ao laboratório de informática (Figura 1), observou-se que sua estrutura física é excelente, contando com 17 computadores, uma impressora e sistema operacional Linux Educacional 4.0. Observou-se que 0 ambiente de informática para ministrar as aulas facilita o fluxo das professoras e dos alunos, permitindo a interação, a colaboração e a cooperação entre os alunos e, também, proporcionando às professoras melhor visualização das atividades desenvolvidas por eles. A topologia é do tipo barramento e a Internet é restrita ao laboratório de informática, um ponto positivo para desenvolver atividades significativas e motivadoras junto aos alunos.

\section{Figura 1: Laboratório de Informática da escola}




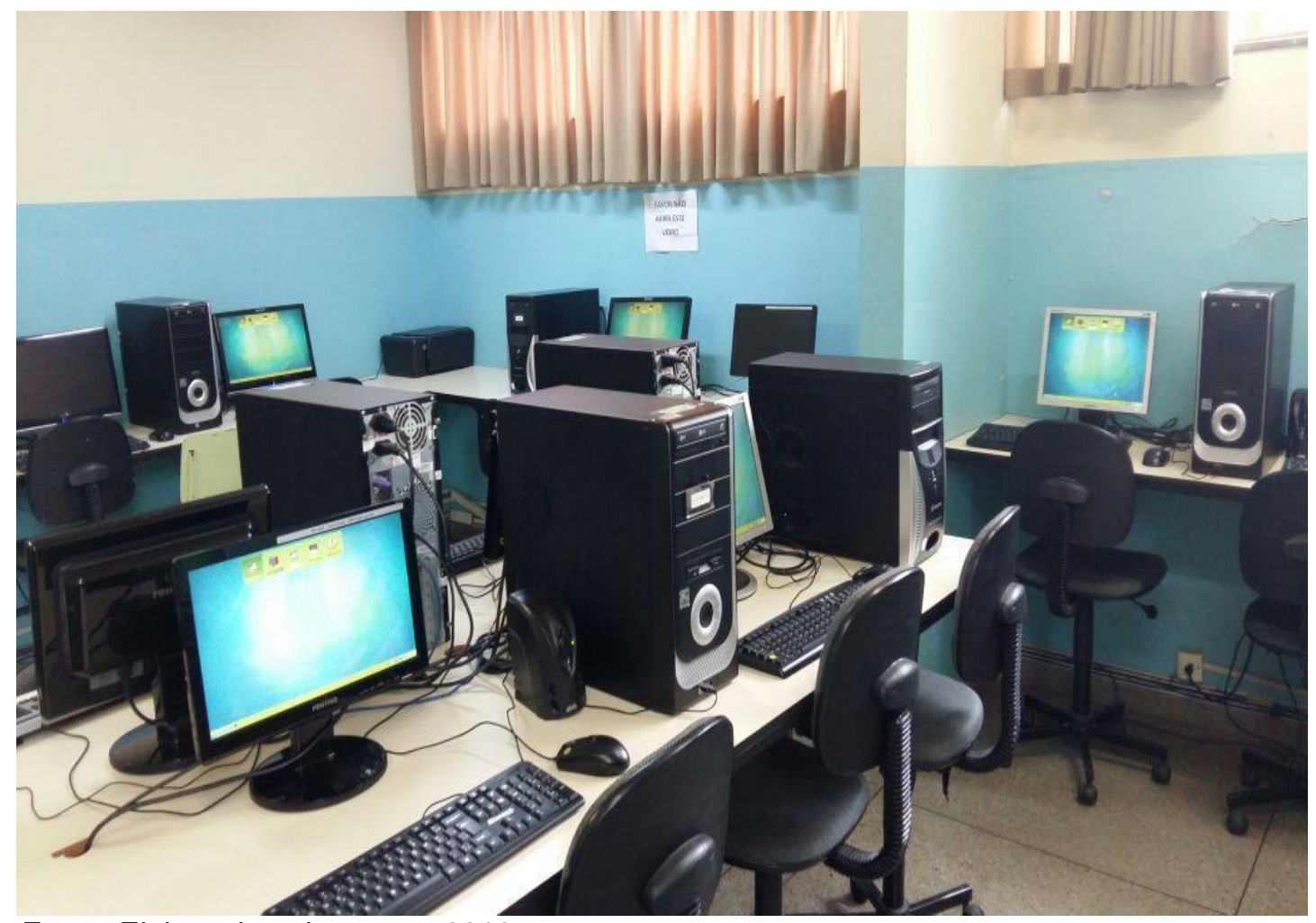

Fonte: Elaborado pela autora, 2019.

No que tange aos alunos, vinte e cinco alunos (12 meninos e 13 meninas) que estudam no $5^{\circ}$ ano do Ensino Fundamental, foram os sujeitos dessa pesquisa. Eram alunos com idade média de 10 a 12 anos. Todos eram usuários de computador e possuíam domínio da ferramenta, uma vez que eles tinham a oportunidade de vivenciar no laboratório de informática da própria escola e em casa.

As ações desenvolvidas aconteceram durante o mês de abril de 2019 e num período de quinze dias, somando quatro encontros: dois na primeira semana de abril e dois na segunda semana. A duração dos encontros foi de 60 minutos no Laboratório de Informática da escola. Os alunos foram divididos em duplas.

No primeiro encontro, a professora regente fez uma revisão com os alunos sobre o gênero textual história em quadrinhos e seus elementos básicos. Logo em seguida, foi apresentado aos alunos o software HagáQuê com as devidas explicações sobre como manusear o mesmo. Os alunos puderam entrar no programa que já estava instalado em todas as máquinas do laboratório e aprender a mexer no "Menu Figura", a posicionar os elementos dentro de cada cenário e a utilizar o recurso "Ferramentas de Edição".

Como o "Menu Figura" apresenta 09 botões, explicamos apenas os botões "cenário colorido", "cenário preto e branco", "personagem colorido", 
"personagem preto e branco", objeto colorido", “objeto preto e branco". Os alunos ficaram livres para montar a história que quisesse, utilizando-se apenas desses recursos. Nas imagens abaixo, podemos verificar o trabalho inicial dos alunos:

\section{Figura 2: HagáQuê Cenário}

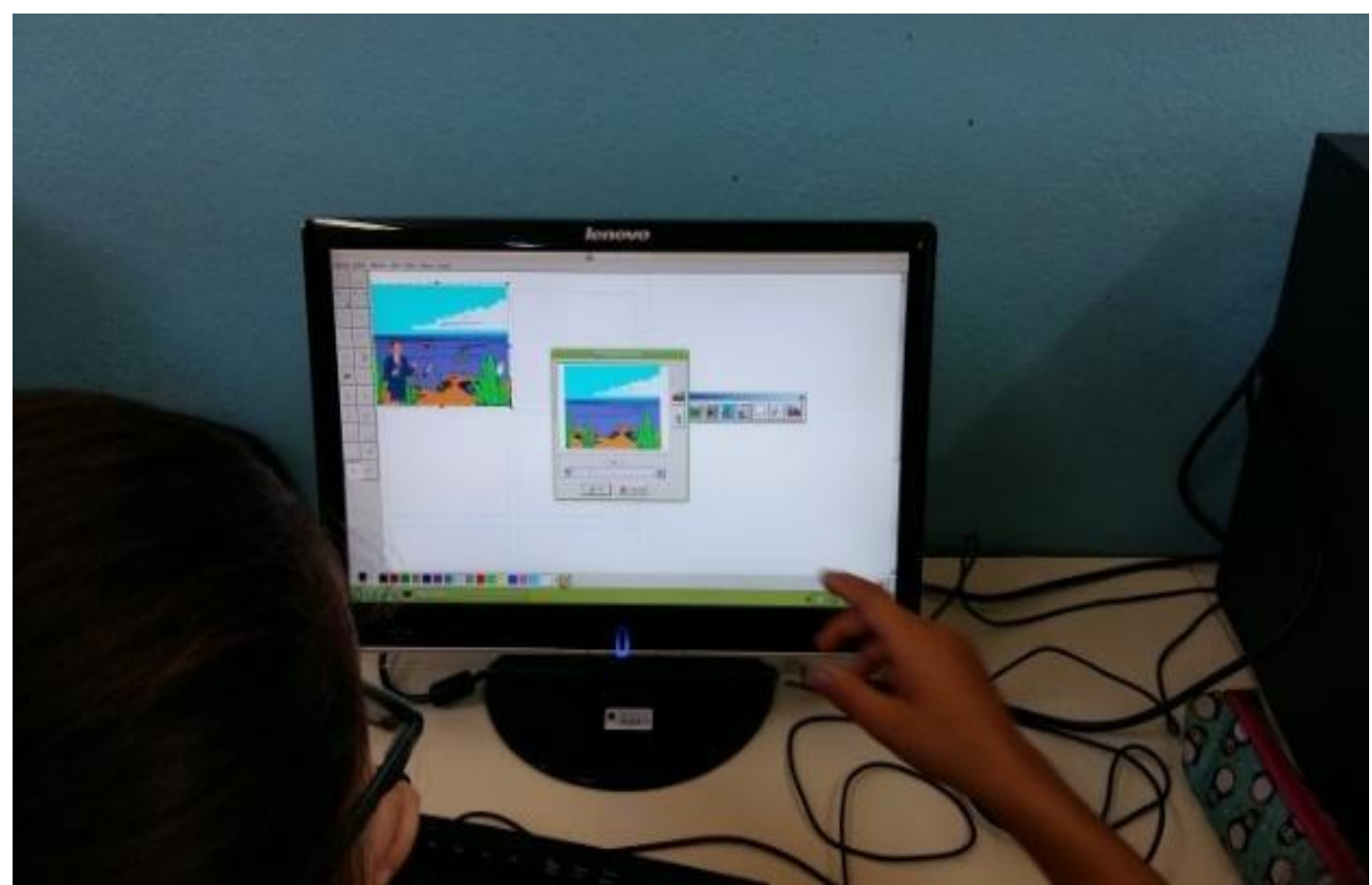

Fonte: Elaborado pela autora, 2019.

Figura 3: HagáQuê Personagens

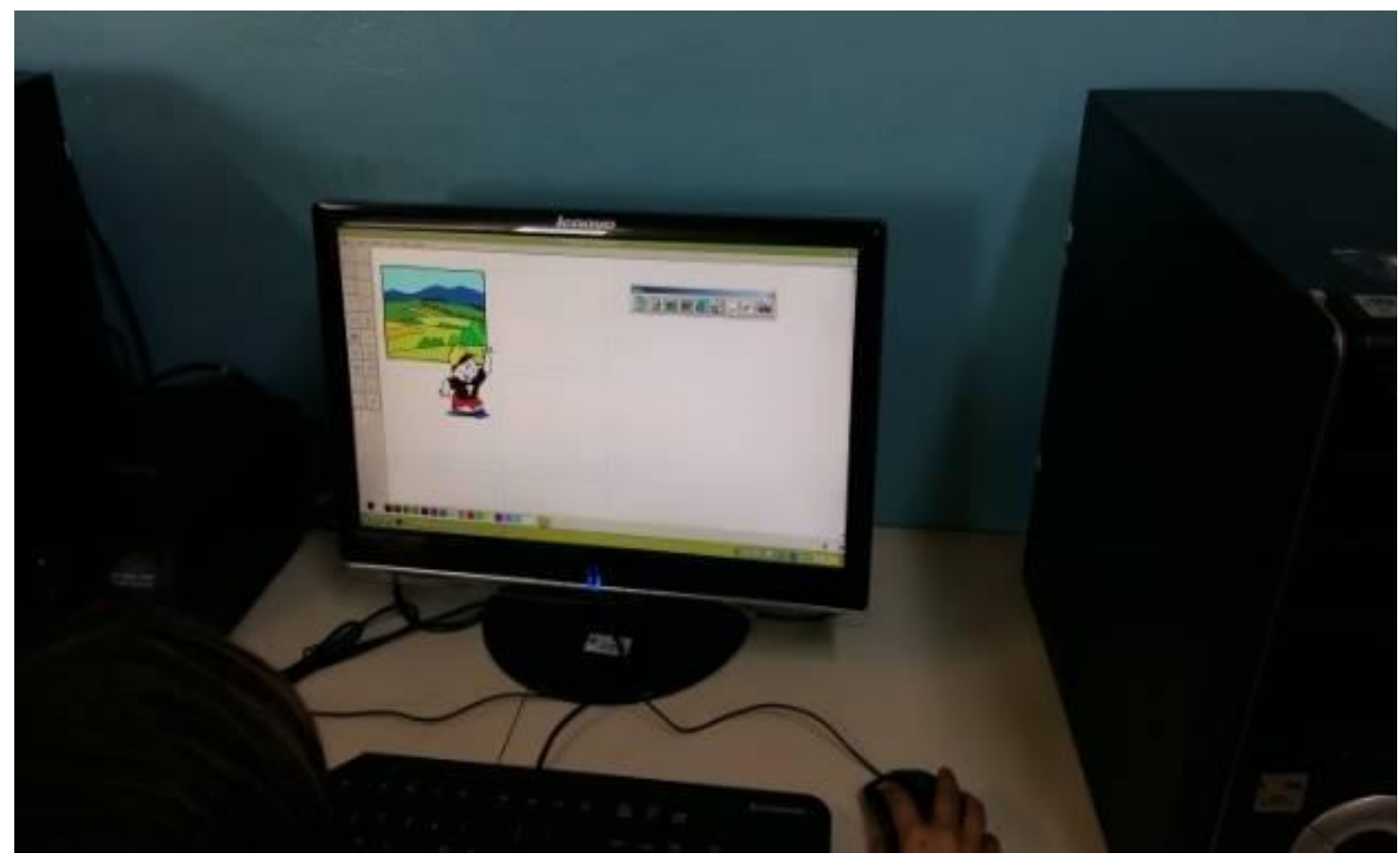

Fonte: Elaborado pela autora, 2019. 


\section{Figura 4: HagáQuê Objetos}

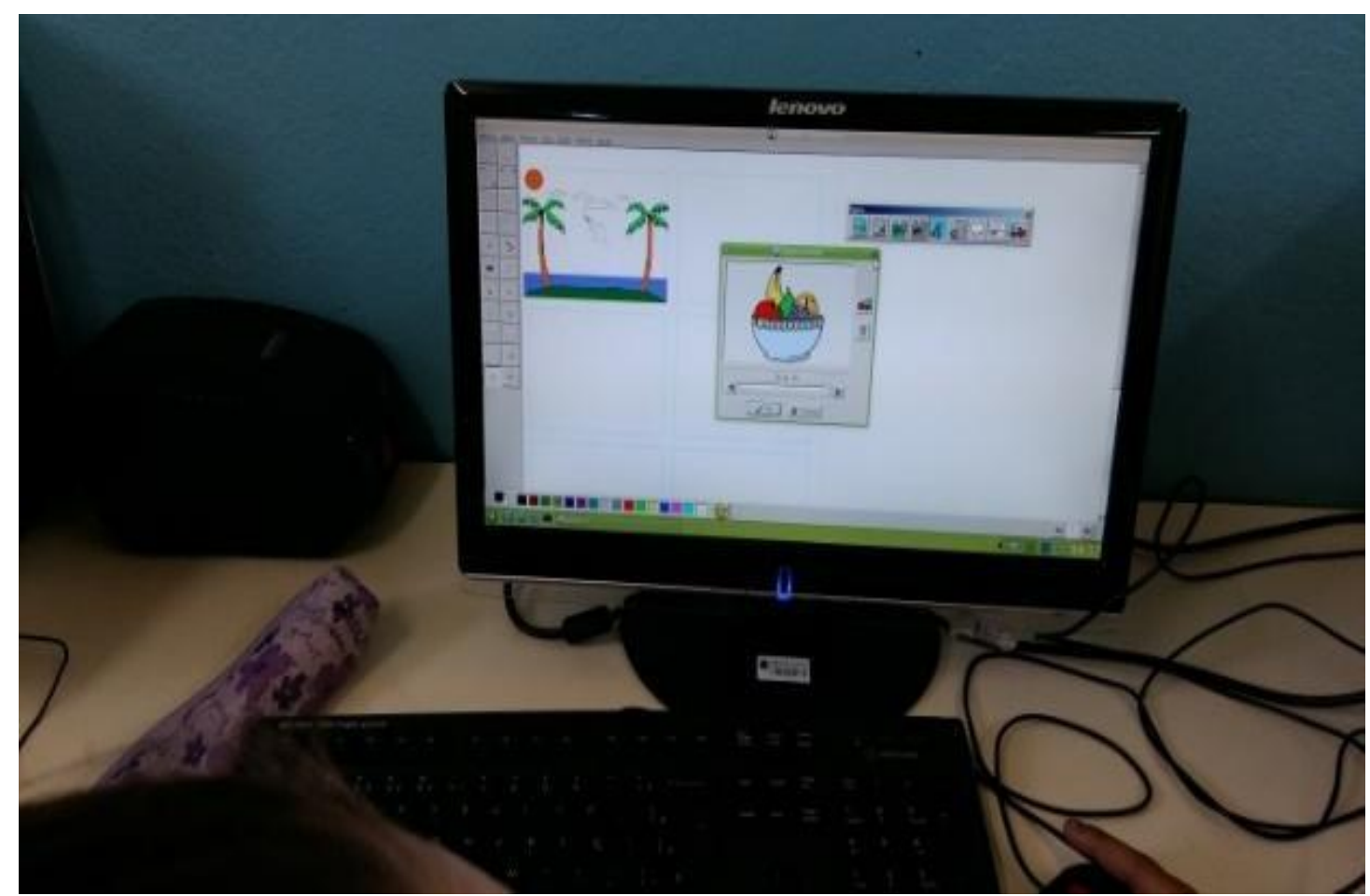

Fonte: Elaborado pela autora, 2019.

No segundo encontro, demos continuidade ao trabalho apresentando os outros botões: "balão" e "onomatopéia". Além disso, ensinamos como escrever e posicionar dentro dos balões, bem como aprender a salvar a história criada. Os alunos, também, ficaram livres para criar a história conforme podemos observar na sequência de imagens abaixo: 
Figura 5: HagáQuê Onomatopéia e Balões

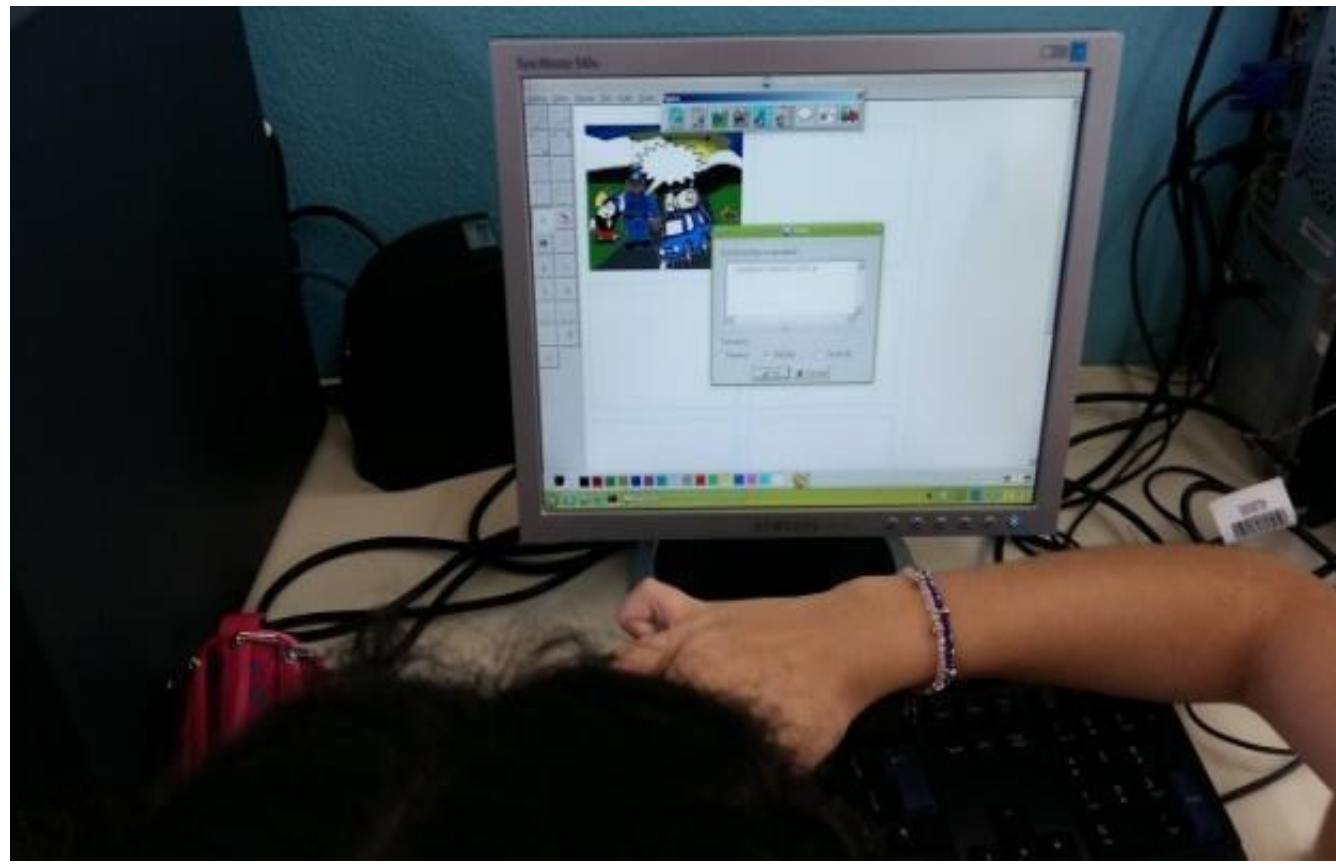

Fonte: Elaborado pela autora, 2019.

Figura 6: Criação livre

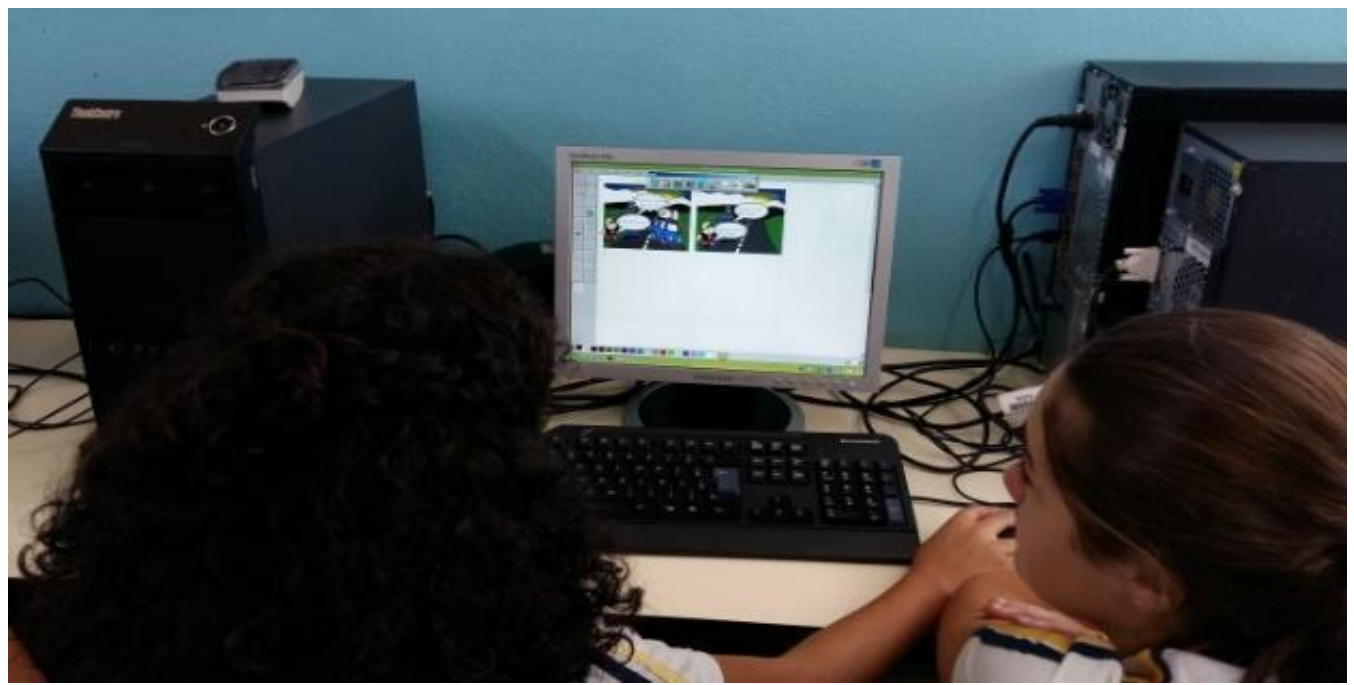

Fonte: Elaborado pela autora, 2019.

No terceiro encontro, a professora solicitou que os alunos criassem uma história em quadrinhos contendo quatro cenários e com o tema Meio Ambiente, a partir dos textos trabalhados em sala de aula sobre consciência ambiental.O início do trabalho dos alunos pode ser verificado abaixo através de algumas imagens:

Figura 7: Criação da história 

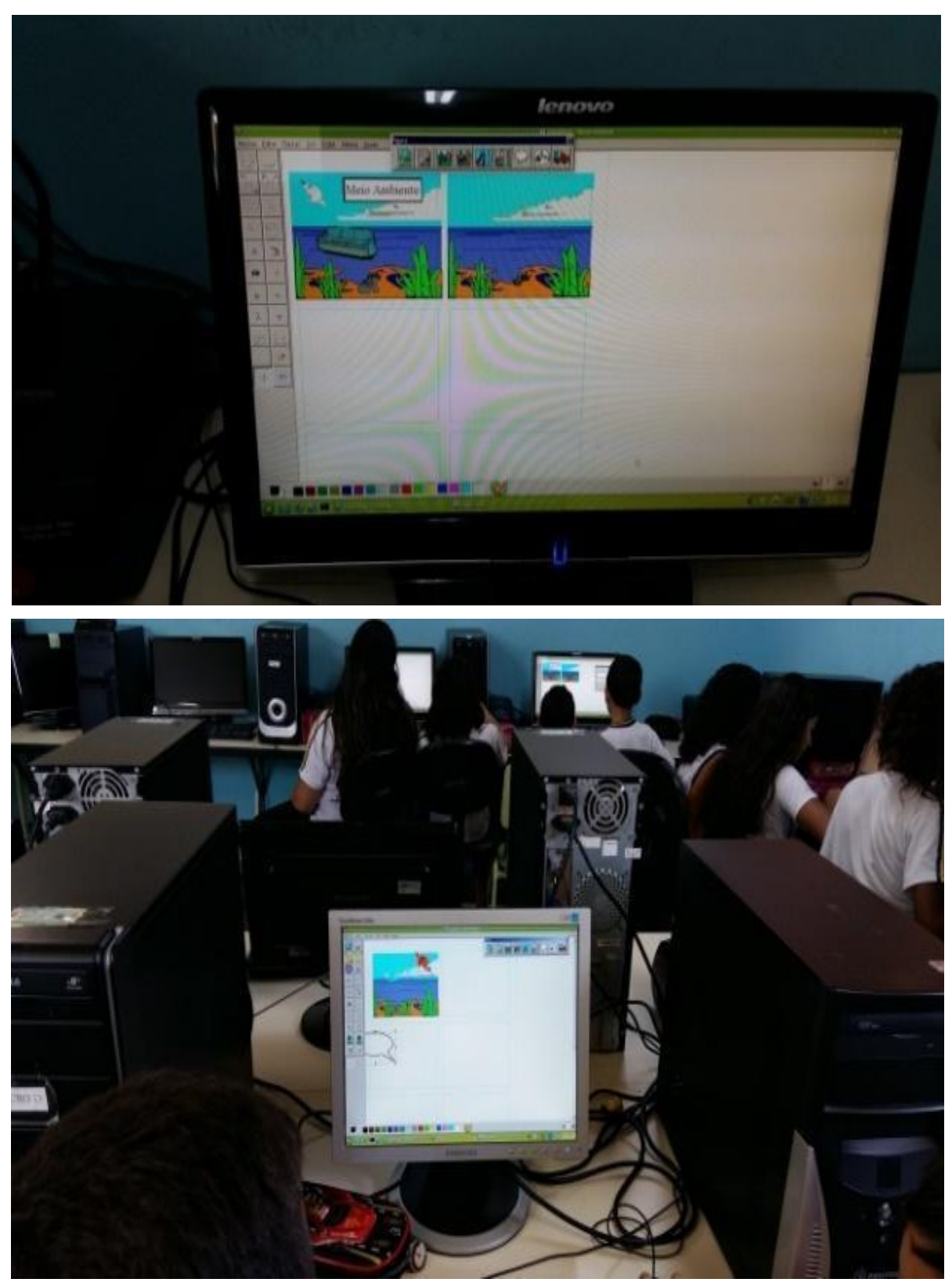


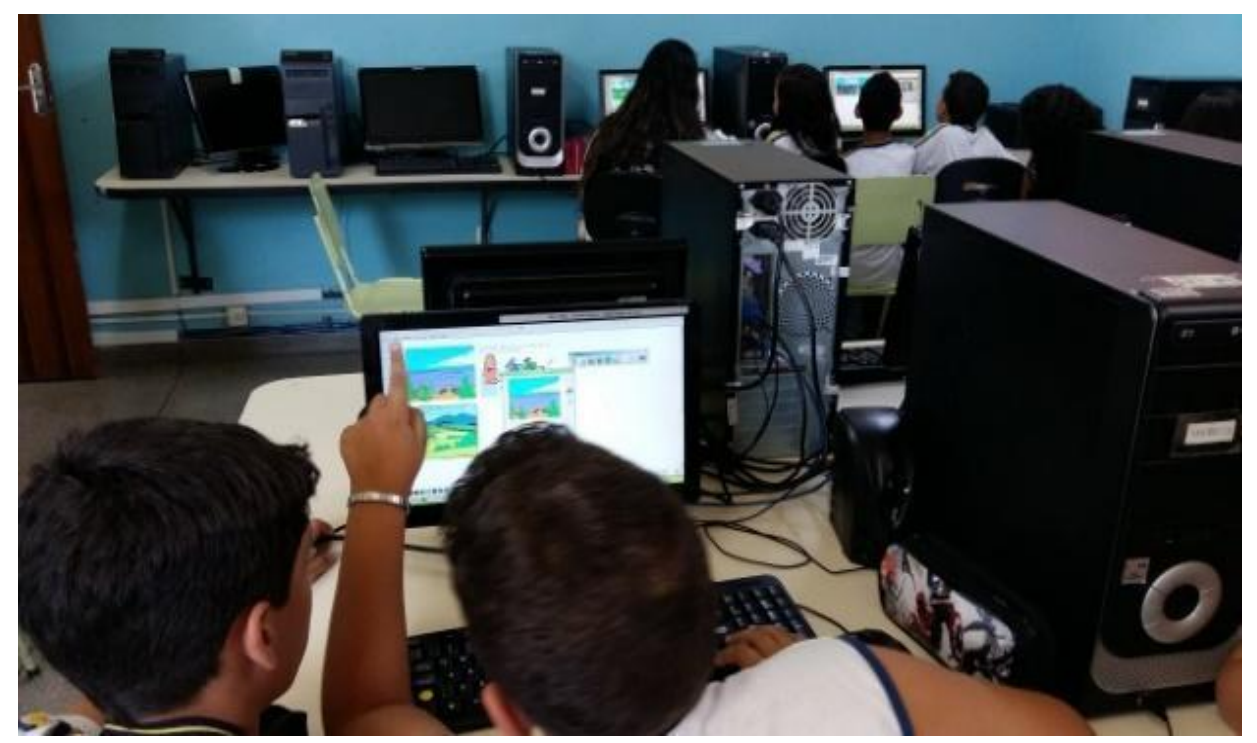

Fonte: Elaborado pela autora, 2019.

No quarto e último encontro, os alunos puderam fazer ajustes nas histórias criadas, verificar erros ortográficos e sinais de pontuação. Todas as histórias foram salvas no computador da escola. Abaixo segue o resultado final das histórias criadas pelos alunos com a temática proposta pela professora.

Figura 8: HagáQuê e Resultado Final

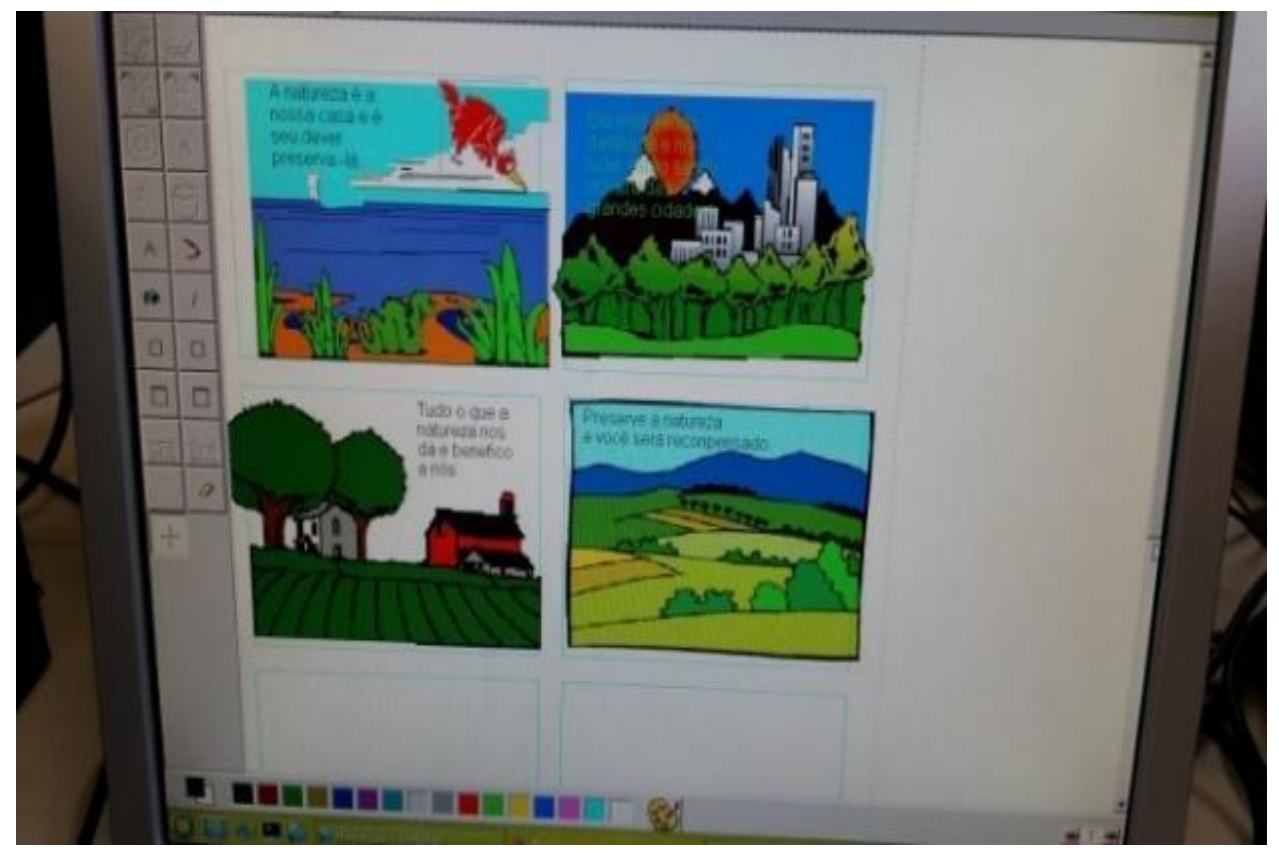



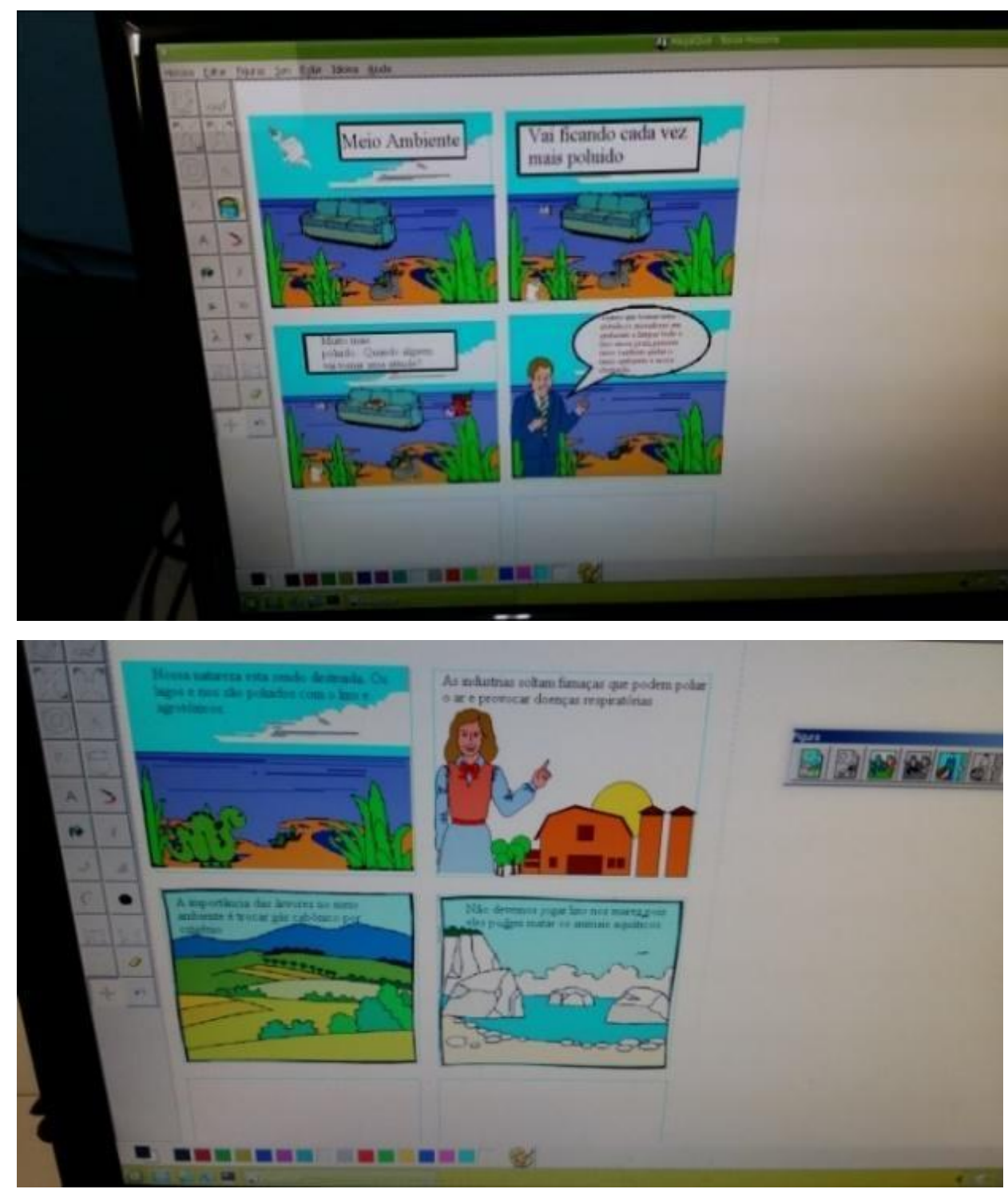

Fonte: Elaborado pela autora, 2019.

Diante de tais resultados observados durante a pesquisa de campo, verificou-se que é fundamental conhecer e analisar os vários recursos que estão à disposição do professor para a produção de trabalhos com qualidade.

Observa-se que a junção entre softwares educativos e conteúdo escolar permite a realização de diversas tarefas e mostra-se um excelente caminho para a aprendizagem dos alunos. Na prática, verificou-se que o software HagáQuê enquadra-se na categoria de software de autoria e com a presença de uma fundamentação pedagógica baseada no interacionismo. Os alunos participaram ativamente da construção da história em quadrinhos em que a descoberta, experimentações, questionamentos, colaboração, criação e o erro como fonte de aprendizagem foram alguns dos ingredientes observados durante a execução da atividade. Outro fator a ser destacado refere-se à postura da professora que acompanhou a evolução e fez intervenções adequadas durante o processo, em uma relação de parceria. 
A análise das histórias em quadrinhos criadas pelos alunos com a ajuda do software HagáQuê revela que o trabalho relacionado ao domínio da leitura e escrita satisfaz aos conceitos de alfabetização e letramento discutidos pela autora Soares $(1998,2003 b)$. Verificou-se que por todos os alunos serem alfabetizados e com domínio do sistema convencional da escrita e leitura, foi possível fazer o uso desse processo em sua amplitude ao proporcionar aos alunos o desenvolvimento de competências e habilidades sobre 0 uso consciente da leitura e escrita através de suas ideias e argumentos sobre questões que fazem parte do seu cotidiano como, por exemplo, a questão ambiental discutida e trabalhada por eles.

Em relação ao trabalho desenvolvido no contexto digital, observou-se que a efetividade da prática da leitura e escrita ocorreu de forma mais atraente e contextual. Através do software HagáQuê, a professora teve a oportunidade de explorar novas formas de leitura e escrita com os alunos, proporcionando novas formas de transmissão e articulação do conhecimento adquirido em sala de aula. Outro aspecto importante a destacar é que o processo de alfabetização e letramento tem sido favorecida pelo uso do computador, com destaque para o uso do software HagáQuê, potencializando a capacidade de aprendizagem da leitura e escrita desses alunos, em processos de ensino e aprendizagem mais dinâmicos.

\section{CONCLUSÕES}

Nesse caminhar, verificamos que o emprego da tecnologia, em especial o computador, no ambiente escolar que vem se solidificando e se destacando. Por que não aliar seu uso ao conteúdo das disciplinas, em especial, à Língua Portuguesa e auxiliar no processo de leitura e escrita em contextos digitais? Tal questionamento foi apontado no início das discussões e verificado durante a realização da pesquisa. O computador é elemento marcante e atrativo para os alunos, além de enriquecer o processo de aprendizagem. Não deve ser pensado apenas como ferramenta restrita e, sim, como ferramenta a serviço do saber e do saber-fazendo.

Interligado a essa ferramenta, temos os softwares educativos para auxiliar no processo de alfabetização e letramento. O software educativo HagáQuê mostrou-se ser uma ferramenta interessante para esse processo ao permitir atividades lúdicas e prazerosas, além de provocar um interesse para uma maior aproximação com as funções sociais da linguagem. Através da "escrita digitalizada", os alunos puderam compor diferentes personagens, inseridos em diversos contextos, conhecer a estrutura de histórias em quadrinhos e produzir textos. 
Conclui-se, portanto, que o trabalho mediado com o computador e seus recursos traz sentido ao que os alunos aprendem em sala de aula. Um bom planejamento, articulação com os conteúdos trabalhados, professores capacitados e integração ao projeto político pedagógico da escola são aspectos que podem fazer a diferença no uso consciente dessa tecnologia ao processo educacional.

\section{REFERÊNCIAS}

ALVES, Vanessa Santos; SILVA, Bruna Fernandes da; SANTOS, Fernanda Maria Almeida do. A alfabetização em contextos digitais: dificuldades, avanços e desafios. In: FÓRUM INTERNACIONAL DE PEDAGOGIA, 5, 2013; Vitória da Conquista-BA. Anais [...] UESB: Fórum Internacional de Pedagogia, 2013. Disponível em: http://www.editorarealize.com.br/revistas/fiped/resumo.php?idtrabalho=342. Acesso em: 21 out. 2018.

BRASIL. Secretaria de Educação Fundamental. Parâmetros Curriculares Nacionais: Língua Portuguesa. Brasília, MEC/SEF, DF: Secretaria de Educação Fundamental,1997. Disponível em: http://portal.mec.gov.br/seb/arquivos/pdf/livro02.pdf. Acesso em: 23 set. 2018.

BOGDAN, Robert; BIKLEN, Sari. Investigação qualitativa em educação: uma introdução à teoria e aos métodos. Porto: Porto Editora, 1994.

CARDOSO, Beatriz; EDNIR. Madza. Ler e escrever, muito prazer! São Paulo: Ática, 1998.

FERREIRA, Márcia Helena Mesquista; FRADE, Isabel Cristina Alves S. Alfabetização e Letramento em contextos digitais: pressupostos de avaliação aplicados ao software HagáQuê. In: RIBEIRO, Ana Elisa et al. (Orgs). Linguagem, Tecnologia e Educação. São Paulo: Peirópolis, 2010. Cap. 1, p. 15-27.

GADOTTI, Moacir. Perspectivas atuais da educação. Revista São Paulo em Perspectiva, v. 14, n.2, p. 03-11, 2000. Disponível em:

http://www.scielo.br/pdf/spp/v14n2/9782.pdf. Acesso em: 23 set. 2018.

GONÇALVES, Jane Bianca Duquia; LAMMEL, luri. Uso do editor HagáQuê na educação de crianças entre 8 e 9 anos do município de Cachoeira do Sul. Manancial: Repositório Digital da UFSM 2013. Disponível em:

http://repositorio.ufsm.br/handle/1/600. Acesso em: 10 out. 2018.

GUIMARÃES, Edgard. História em quadrinhos como instrumento educacional. In: Sociedade Brasileira de Estudos Interdisciplinares da Comunicação, 24, 2001; Campo Grande-MS. Anais [...] Campo Grande: Congresso Brasileiro da Comunicação, 2001. Disponível em: http://www.portcom.intercom.org.br/pdfs/1291511374377819995905709522414699511 26.pdf. Acesso em: 26 set. 2018.

KENSKI, Vani M. Tecnologias e ensino presencial e a distância. 2. ed. Campinas: Papirus, 2004. 
LISBOA, Patrícia. Os softwares educativos e a construção de habilidades cognitivas na pré-escola. Revista Práticas de Linguagem, Juiz de Fora, v. 3, n.1, p. 13-22, jan./jun.2013.

MARINHO, Vanessa C. O cenário do uso das tecnologias na escola do século XXI. In: WORKSHOP DE INFORMÁTICA NA ESCOLA, 19, 2013; Unicamp-SP. Anais [...] Unicamp: Congresso Brasileiro de Informática na Educação, 2013. Disponível em: http://www.br-ie.org/pub/index.php/wie/article/view/2605/2261. Acesso em: 25 set. 2018.

OLIVEIRA, Celina Couto de; COSTA, José Wilson da; MOREIRA, Mercia. Ambientes informatizados de aprendizagem: produção e avaliação de software educativo. Campos, SP: Papirus, 2001.

O QUE É LETRAMENTO? Diário na Escola, Santo André, p.03, 29 ago.

2003a.Disponível em: http://www.verzeri.org.br/artigos/003.pdf. Acesso em: 17 out. 2018.

PRADO, Juliana Santo Sosso. Agora é hora: alfabetização. Curitiba, PR: Base Editorial, 2011.

SILVA, Bruna Camargo da et al. Jogos digitais educacionais como instrumento didático no processo de ensino-aprendizagem das operações básicas de matemática. In: SIMPÓSIO BRASILEIRO DE INFORMÁTICA NA EDUCAÇÃO, 25, 2014, Dourados. Anais [...] Dourados: Congresso Brasileiro de Informática na Educação, 2014. Disponível em: http://www.br-

ie.org/pub/index.php/sbie/article/view/2999. Acesso em: 04 out. 2018.

SILVA, Marília Gerlane Guimarães da. O uso do software HagáQuê como ferramenta pedagógica na construção de histórias em quadrinhos: auxiliando no processo de ensino e aprendizagem. Campina Grande, 2012. p. 37. Trabalho de Conclusão de Curso (Graduação em Pedagogia) - Universidade Estadual da Paraíba, Centro de Educação, Campina Grande, 2012.

SOARES, Magda. Letramento: um tema em três gêneros. Belo Horizonte, Autêntica, 1998.

SOARES, Magda. Letramento e alfabetização: muitas facetas. Revista Brasileira de Educação, n. 25, p. 04-17, jan./fev./mar./abr. 2003b. Disponível em:

http://www.scielo.br/pdf/rbedu/n25/n25a01.pdf. Acesso em: 18 out. 2018.

SOFFA, Marilice Mugnaini; ALCÂNTARA, Paulo Roberto de Carvalho. $\mathbf{O}$ uso do software educativo: reflexões da prática docente na sala informatizada. In: CONGRESSO NACIONAL DE EDUCAÇÃO, 8, 2008, Curitiba. Anais [...] Curitiba: Congresso Nacional de Educação, 2008. Disponível em: < www.pucpr.br/eventos/educere/educere2008/anais/pdf/335_357.pdf. Acesso em: 10 out. 2018.

VALENTE, José Armando. O computador na sociedade do conhecimento. Campinas, SP: UNICAMP/NIED, 1999.

VALENTE, J. A.; ALMEIDA, F. J. Visão analítica da informática na Educação no Brasil: a questão da formação do professor. Revista Brasileira de Informática na Educação, Florianópolis, n. 1, p. 45-60, set. 1997. Disponível em 
O uso do Software HagáQuê nos anos iniciais do ensino fundamental: práticas de letramento em contextos digitais

http://www.inf.ufsc.br/sbcie/revista/nr1/valente.html. Acesso em: 10 out. 2018. 